Article

\title{
Preparation and Characterization of High Thermal Conductivity and Low CTE Polyimide Composite Reinforced with Diamond Nanoparticles/SiC Whiskers for 3D IC Interposer RDL Dielectric
}

\author{
Jiangbo Luo ${ }^{1}{ }^{\mathbb{D}}$, Yongpeng Wu ${ }^{1}$, Yunna Sun ${ }^{1}$, Guilian Wang ${ }^{2}$, Yanmei Liu ${ }^{1}$, Xiaolin Zhao ${ }^{1}$ \\ and Guifu Ding ${ }^{1, *}$ \\ 1 National Key Laboratory of Science and Technology on Micro/Nano Fabrication, School of Electronic \\ Information and Electrical Engineering, Shanghai Jiao Tong University, Shanghai 200240, China; \\ luojiangbo316@163.com (J.L.); wuyongpeng@sjtu.edu.cn (Y.W.); cecilia_sun@sjtu.edu.cn (Y.S.); \\ ymaibc@163.com (Y.L.); xlzhao@sjtu.edu.cn (X.Z.) \\ 2 School of Electronic and Electrical Engineering, Shanghai University of Engineering Science, \\ Shanghai 201620, China; wglwrc2016@126.com \\ * Correspondence: gfding@sjtu.edu.cn
}

Received: 27 March 2019; Accepted: 8 May 2019; Published: 13 May 2019

\begin{abstract}
Low thermal conductivity and large coefficient of thermal expansion (CTE) are the most serious disadvantages of the polymer dielectric for the interposer redistribution layer (RDL). In this paper, a high thermal conductivity and low CTE composite with polyimide (PI) matrix and diamond nanoparticles/SiC whiskers reinforcement is proposed. The preparation and characterization of the composite film are presented and the effects of the composite on the improvement of the interposer properties are investigated. With $10 \mathrm{wt} \%$ diamond-nanoparticles and $7 \mathrm{wt} \% \mathrm{SiC}$-whiskers, the composite film has a thermal conductivity of $1.63 \mathrm{~W} / \mathrm{m} \cdot \mathrm{K}$ and a CTE of $16.7 \mathrm{ppm} /{ }^{\circ} \mathrm{C}$ (compared with $0.19 \mathrm{~W} / \mathrm{m} \cdot \mathrm{K}$ and $55.6 \mathrm{ppm} /{ }^{\circ} \mathrm{C}$ of the PI). Interposers with PI RDL dielectric and the composite RDL dielectric are fabricated, respectively. The simulation result shows that the composite dielectric can significantly enhance the properties of the interposer compared with the PI dielectric. The thermal resistance of the interposer decreases from $8.04{ }^{\circ} \mathrm{C} / \mathrm{W}$ to $1.15{ }^{\circ} \mathrm{C} / \mathrm{W}$. The maximum von Mises stress decreases from $72.8 \mathrm{MPa}$ to $16.9 \mathrm{MPa}$ and the warpage decreases from $1.13 \mu \mathrm{m}$ to $0.15 \mu \mathrm{m}$. Thermal distribution tests are performed as well. The results show that the maximum temperature of the interposer decreases from $64{ }^{\circ} \mathrm{C}$ to $45.1{ }^{\circ} \mathrm{C}$. The composite developed in this study can reduce the temperature and enhance the reliability of the chips with interposers. It has the potential to expand the application of the interposers in high thermal density integration and high reliability devices.
\end{abstract}

Keywords: diamond nanoparticle; $\mathrm{SiC}$ whisker; polyimide; high conductivity composite; interposer; redistribution layer dielectric

\section{Introduction}

Development of the 3D integrated circuit (IC) integration is driven by the demands for further miniaturization of device, higher integration density, lower power consumption and better performance [1-4]. Si interposer technology is one of the promising solutions for the 3D IC integration which is usually used to stack active chips on a passive Si interposer with through silicon vias (TSVs) as shown in Figure 1a [5,6]. The horizontal electrical interconnection between chips and chips, chips and TSVs is realized through the redistribution layer (RDL) which incorporates multilevel routing layers and dielectric layers [7]. 


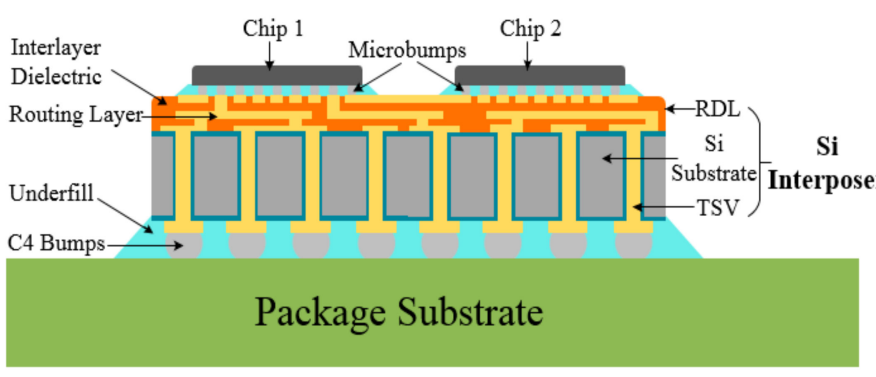

(a)

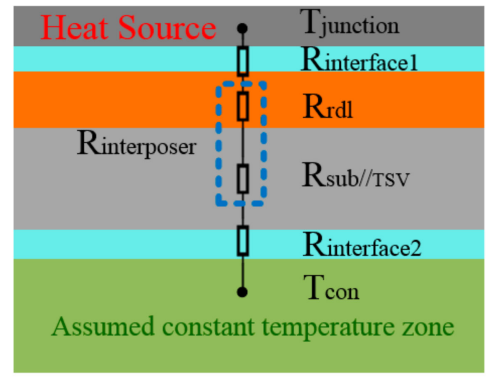

(b)

Figure 1. (a) Si interposer integration and (b) its heat conduction path.

Depending on the material, the RDL dielectrics can be divided mainly into two categories: deposited inorganic dielectrics and spin-coated polymer dielectrics. The deposited inorganic dielectrics include $\mathrm{SiO}_{2}, \mathrm{Si}_{3} \mathrm{~N}_{4}, \mathrm{AlN}$, etc. and the spin-coated polymer dielectrics include Polyimide (PI), Benzocyclobutene (BCB), Poly arylene ether, SiLK, Polysiloxane and so on [8-10]. Spin-coated polymer dielectrics are widely used in 3D IC integration for the advantages of low cost, low relative permittivity (leading to low parasitic capacitance and low resistance-capacitance delay) and the convenience in planarization (especially for multilevel metallization). However, there are several disadvantages for the use of the polymer as RDL dielectric. One serious drawback is its poor thermal conductivity that works as a thermal barrier to heat flow. As the integration density increases, more localized heat is produced and reliability problems become critical. The low thermal conductivity of the polymer dielectric aggravates these problems related to thermal concentration and thermal stress [11,12]. It is worth noting that, although the dielectric layer occupies only a small fraction of the Si interposer in thickness, it provides the majority of the thermal resistance through the heat conduction path $\left(R_{\text {interposer }}=R_{\text {rdl }}+R_{\text {sub/TSV }}\right.$, as illustrated in Figure 1b). According to the study presented by Pinel et al. [13], the $3 \mu \mathrm{m}$ thick polymer dielectric film of the chip has a thermal resistance $\left(2.31^{\circ} \mathrm{C} / \mathrm{W}\right)$ four times larger than that of the $\mathrm{Si}$ substrate of $500 \mu \mathrm{m}$ thick $\left(0.46^{\circ} \mathrm{C} / \mathrm{W}\right)$. This indicates that more than $80 \%$ of the thermal resistance is provided by the polymer dielectric in this polymer dielectric/Si substrate structure. Thus, improving the thermal conductivity of the polymer dielectric is crucial to the heat dispassion of Si interposer. Another disadvantage of the polymer dielectric is its large coefficient of thermal expansion (CTE) (e.g., PI: $\sim 30-60 \mathrm{ppm} /{ }^{\circ} \mathrm{C}$ ) compared with the interposer substrate $\left(\mathrm{Si}: 2.6 \mathrm{ppm} /{ }^{\circ} \mathrm{C}\right.$ ) and routing layer (Cu: $17 \mathrm{ppm} /{ }^{\circ} \mathrm{C}$ ) [9]. The CTE mismatch among RDL dielectric, substrate and routing layer intensifies the thermal stress in the 3D integration $[14,15]$. Therefore, spin-coated polymer-based dielectrics with high thermal conductivity and low CTE has very good application prospects in the 3D IC integration.

At present, there are many studies focusing on improving the thermal conductivity of polymer by adding in high thermal conductivity particles (also lead to a drop in the CTE due to the low CTE of the particles) [16-24]. Xu et al. proposed a BCB-carbon nanotube (CNT) composite as a bonding interface material [16]. An 80\% improvement in thermal conductivity is achieved with the CNT concentration at $1.5 \mathrm{wt} \%$. Anri et al. developed a novel polymer composite as thermal interface material with silicone matrix and fillers of diamond and hexagonal boron nitride platelets [17]. The composite has a maximum thermal conductivity of $6.1 \mathrm{~W} / \mathrm{m} \cdot \mathrm{K}$ with the filler concentration at $90 \mathrm{wt} \%$. Xie et al. presented a PI/AlN composite with an enhanced thermal conductivity of $0.8 \mathrm{~W} / \mathrm{m} \cdot \mathrm{K}$ compared with $0.22 \mathrm{~W} / \mathrm{m} \cdot \mathrm{K}$ of PI [18]. From these studies, it can be concluded that the thermal conductivity of the polymer can be significantly improved by adding in high thermal conductivity particles. However, the composites presented in these studies are mainly developed for bonding interface, thermal interface, surface coating or electrical packaging, most of which are not suitable to be used as RDL dielectric. For example, in Xu's research, the insulation property of the composite is impaired by the CNT fillers, which will induce a large leakage current when the composite is used as RDL dielectric. For the composite developed by Anri, the size of the diamond particles (more than $9 \mu \mathrm{m}$ ) is too large for the thin dielectric layer and the viscosity of the composite is too high for spin-coating process (due to the 
high filler concentration). As presented by Xie, the addition of AlN particles improves the thermal conductivity of the composite, but it also increases the relative permittivity significantly which may cause severe signal delay problems. Thus, besides the enhancement of thermal conductivity and the reduction of CTE, it is essential for the composite to maintain its electrical and mechanical properties to be used as spin-coating dielectric, such as good insulation property, low relative permittivity, good fluidity for spin-coating and enough mechanical strength.

In this paper, the preparation and characterization of a composite with high thermal conductivity and low CTE is presented and its application in interposer RDL dielectrics is discussed as well. The PI is chosen as the matrix for its excellent properties including high elongation at break, good thermal and chemical stability, low relative permittivity and good insulating property [25]. Diamond nanoparticle $(\mathrm{DN})$ and silicon carbide whisker (SCW) are used as reinforcement materials. The DN is chosen for its high thermal conductivity, relatively low electric constant and high resistivity $[17,26]$. The SCW is selected for its better thermal and chemical stability, higher strength, higher elastic modulus and better abrasion resistance compared with other whiskers $[27,28]$. The DNs and SCWs are dispersed into the matrix to form particle-whisker network structures for improving the thermal conductivity, reducing the CTE and reinforcing the mechanical strength of the matrix.

\section{Preparation}

The polyamic acid (PAA), as the precursor of PI, was purchased from the Pome Sci tech Co., Ltd., Beijing, China. This PAA product (ZKPI-305) was of PMDA-ODA type. The chemical structure and the preparation process of the PMDA-ODA type PAA/PI have been extensively studied in previous literature $[22,29,30]$. The N-methyl pyrrolidone (NMP), in which the nanoparticles were pre-dispersed, was obtained from Xuntu Chemical Co., Ltd., Shanghai, China. The DNs were obtained from the Sino-Crystal Micro-Diamond Co., Ltd., Zhengzhou, China, with an average particle size of $50 \mathrm{~nm}$. The SCWs were produced by Sinet Advanced Materials Co. Ltd., Changsha, China, with an average diameter of $300 \mathrm{~nm}$ and lengths ranging from 10 to $50 \mu \mathrm{m}$.

Ball-milling and mechanical stirring experiments were performed to mix the DNs, SCWs and PI coating resin. The result showed that the reinforcement materials were not well dispersed in the matrix when directly mixed together, which might be due to the high viscosity of the PI resin. Figure 2a shows the dispersion result of a direct mixture process ( $8 \mathrm{~h}$ ball-milling followed by $4 \mathrm{~h}$ mechanical stirring). It can be seen that some SCWs were tangled up to form whisker clusters. Furthermore, the SCWs were prone to break off during the ball-milling process, leading to degradation in the enhancement effect. Thus, for the preparation of the composite film, it was a challenge to disperse these two different reinforcement materials in the matrix with uniform distribution.

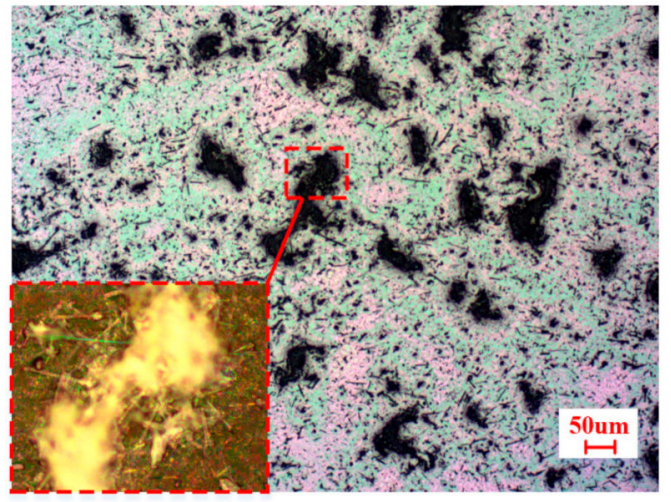

(a)

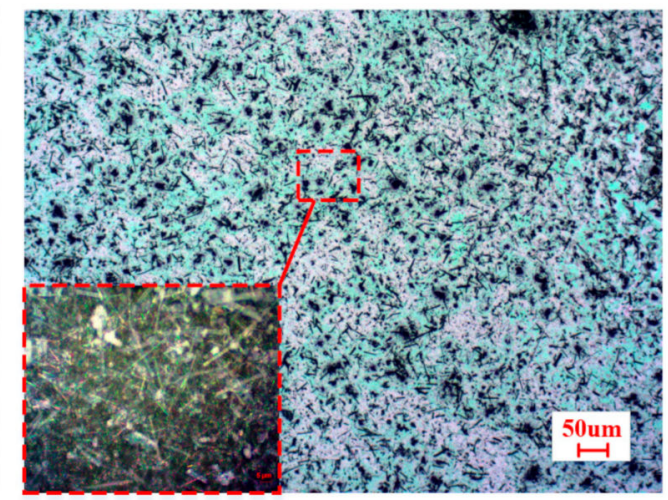

(b)

Figure 2. The diamond nanoparticle (DN)/ silicon carbide whisker (SCW)/ polyimide (PI) composite films prepared by (a) direct mixture process and (b) the pre-dispersion method. 
After a large number of experiments, a mixing method was developed with a good dispersion result. Whiskers and particles are randomly distributed in the matrix as shown in Figure 2b. In this method, the reinforcement materials were pre-dispersed respectively before mixing with PI. The DNs were pre-dispersed in the NMP by ball-milling before mixing with PI. Since the SCWs were not suitable for ball-milling, they were pre-dispersed by a mechanical stirring process in ethanol. The ethanol was chosen as the pre-dispersing matrix for its low viscosity and high volatility. The low viscosity was beneficial for the pre-dispersion of SCWs, and the high volatility was necessary for the subsequent mixing process with PI. Since the ethanol was easy to volatilize during the mixing process, the mixture becomes viscous again to suppress the sedimentation and stratification of the fillers.

The preparation process of the composite film is illustrated in Figure 3. The details are described as follows.

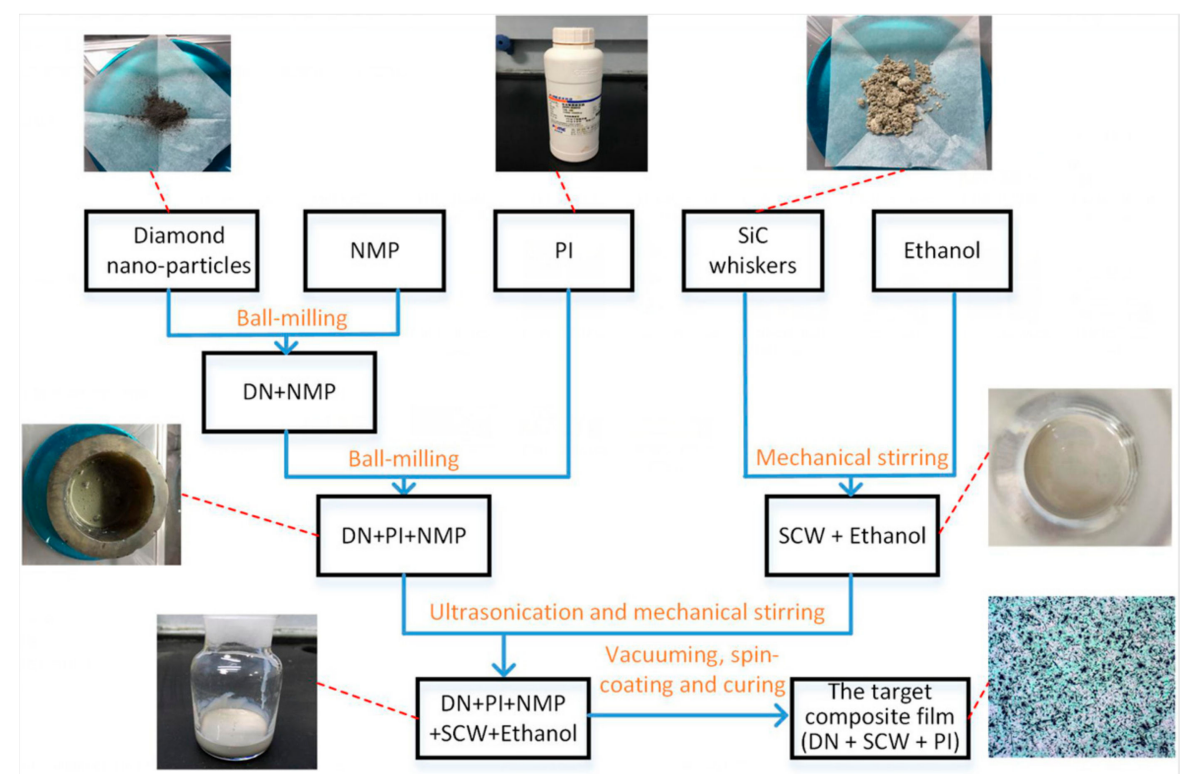

Figure 3. The preparation process of the composite film.

(1) The DNs were mixed with the NMP. Then the mixture was ball-milled for $2 \mathrm{~h}$ with a rotation rate of $500 \mathrm{r} / \mathrm{min}$;

(2) The PI precursor was added into the mixture and then was ball-milled for another $8 \mathrm{~h}$ to fully disperse the nanoparticles in the PI matrix;

(3) The SCWs were added into the ethanol at a mass ratio of 1:20 and then mechanically stirred for $1 \mathrm{~h}$ with a rotation rate of $900 \mathrm{r} / \mathrm{min}$. The vessel was sealed during the stirring process to avoid the volatilization of the ethanol;

(4) The ball-milled DN/PI mixture was added into the SiC/ethanol mixture. Then it was treated with ultrasonication and mechanical stirring alternately. During this process, the vessel was open and the ethanol continued to volatilize. This process took about several hours until most of the ethanol was volatilized and the mixture became viscous;

(5) The DN/SCW/PI composite was placed in vacuum for $20 \mathrm{~min}$ to remove the air from the mixture;

(6) The composite was spin-coated on the silicon wafer;

(7) The wafer was placed in an oven with nitrogen atmosphere and the DN/SCW/PI precursor was cured through a stepped heating process (the same process as curing the PI matrix). The temperature curve is shown in Figure 4. 


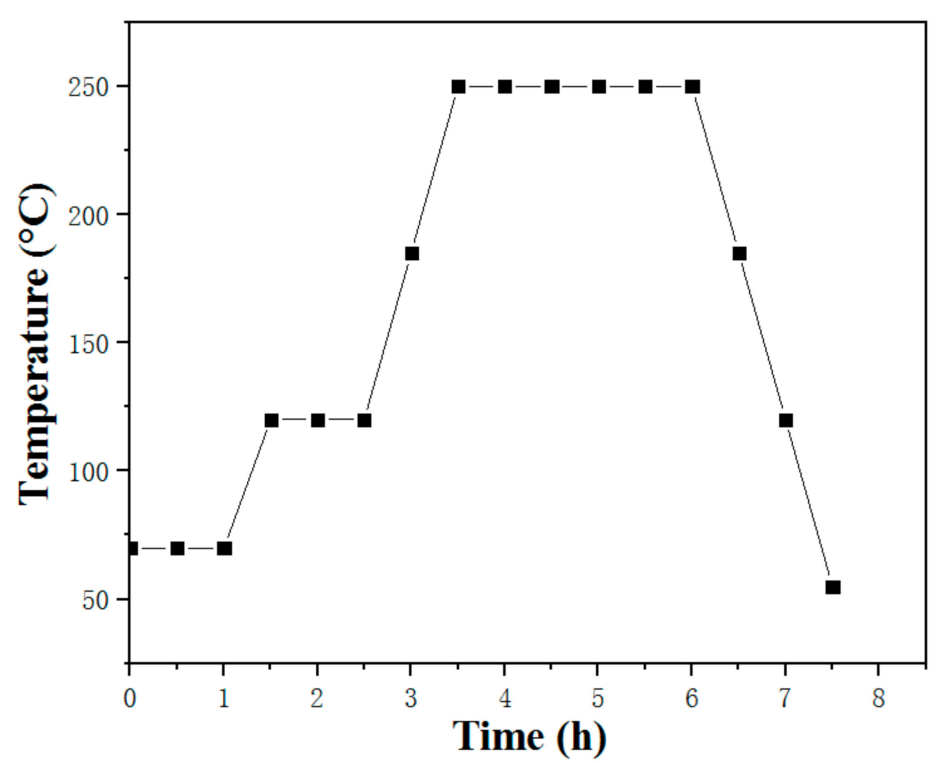

Figure 4. The stepped heating process for curing the composite or PI precursor.

Scanning electron microscopy (SEM) was used to observe the morphology of the composite film. The surface and cross sectional SEM images of the composite film are shown in Figure 5. It can be seen from the images that the DNs and the SCWs were uniformly distributed in the PI matrix and the nanoparticle-whisker network structures were formed. The nanoparticle-whisker network structures can enhance the mechanical strength and improve the thermal conductivity of the composite effectively $[17,28]$.

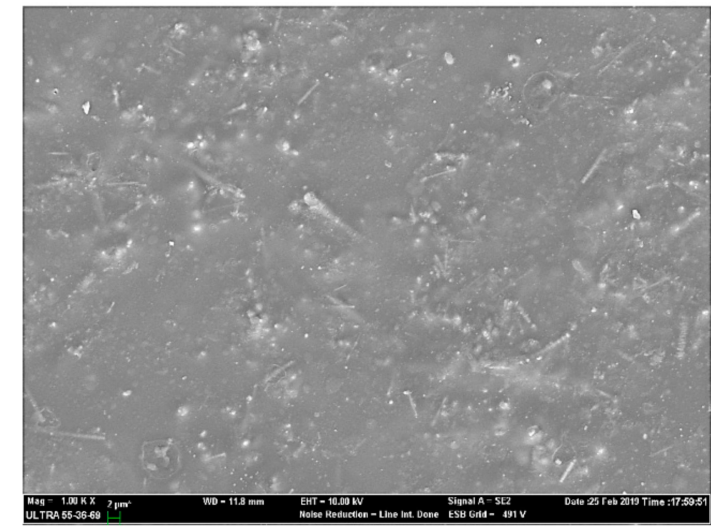

(a)

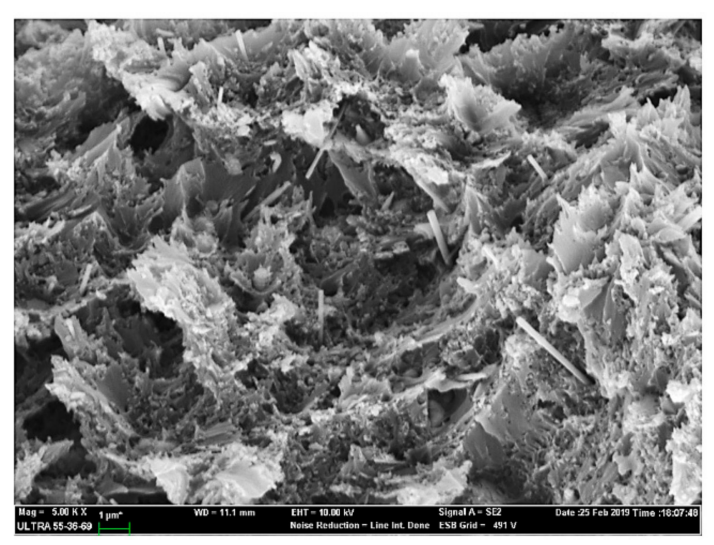

(b)

Figure 5. The surface (a) and cross sectional (b) scanning electron microscopy (SEM) images of the composite film.

\section{Characterization}

A series of tests was carried out to evaluate the performance of this composite as an RDL dielectric including thermal conductivity, CTE, tensile modulus and tensile strength, relative permittivity, insulating property and so on. The mass fractions of the SCWs (in the precursor) of the composite test samples were fixed at $7 \mathrm{wt} \%$ and the mass fraction of the DNs (in the precursor) were $0 \mathrm{wt} \%, 1 \mathrm{wt} \%$, $2.5 \mathrm{wt} \%, 5 \mathrm{wt} \%, 7.5 \mathrm{wt} \%$ and $10 \mathrm{wt} \%$, respectively. According to our early research on the SCW/PI composite [14], good mechanical properties and the highest thermal conductivity of the composite was obtained when the concentration of SCWs was about $7 \mathrm{wt} \%$. Concentrations higher than $7 \mathrm{wt} \%$ would result in a decrease in the performance of the SCW/PI composite due to the agglomeration of 
the whiskers. Instead of adding more SCWs, the addition of an appropriate amount of DNs would further increase the thermal conductivity of the composite without causing agglomeration problems. The highest mass fraction of the DNs was $10 \mathrm{wt} \%$, since more DNs would make the precursor too viscous for the spin-coating process. Moreover, high mass fractions of the inorganic additives make the composite too fragile to be used as RDL dielectric.

\subsection{Thermal Conductivity}

The thermal conductivity of the composite film was calculated according to Equation (1):

$$
\mathrm{k}=\alpha \rho c
$$

where $\alpha, \rho$ and $c$ were the thermal diffusivity, density and specific heat of the film, respectively.

The thermal diffusivity of the film was measured by the laser flash method (LFA 467 HyperFlash, Netzsch) at room temperature of $25^{\circ} \mathrm{C}$. The density was obtained from the immersion method and the specific heat was measured by the differential scan calorimeter (DSC 204F1, Netzsch). The thermal conductivity of the composite film versus different DNs concentrations is shown in Figure 6. As the concentration of the DNs increased, the thermal conductivity of the composite increased accordingly. This indicates that the reinforcement materials were well dispersed in the composite with $10 \mathrm{wt} \%$ DNs and $7 \mathrm{wt} \%$ SCWs. Otherwise, there would have been a decrease in the thermal conductivity caused by the agglomeration. The composite had an excellent thermal conductivity of $1.63 \mathrm{~W} / \mathrm{m} \cdot \mathrm{K}$ with $10 \mathrm{wt} \%$ DNs and $7 \mathrm{wt} \%$ SCWs, when the thermal conductivity of the PI without reinforcement materials was only $0.19 \mathrm{~W} / \mathrm{m} \cdot \mathrm{K}$.

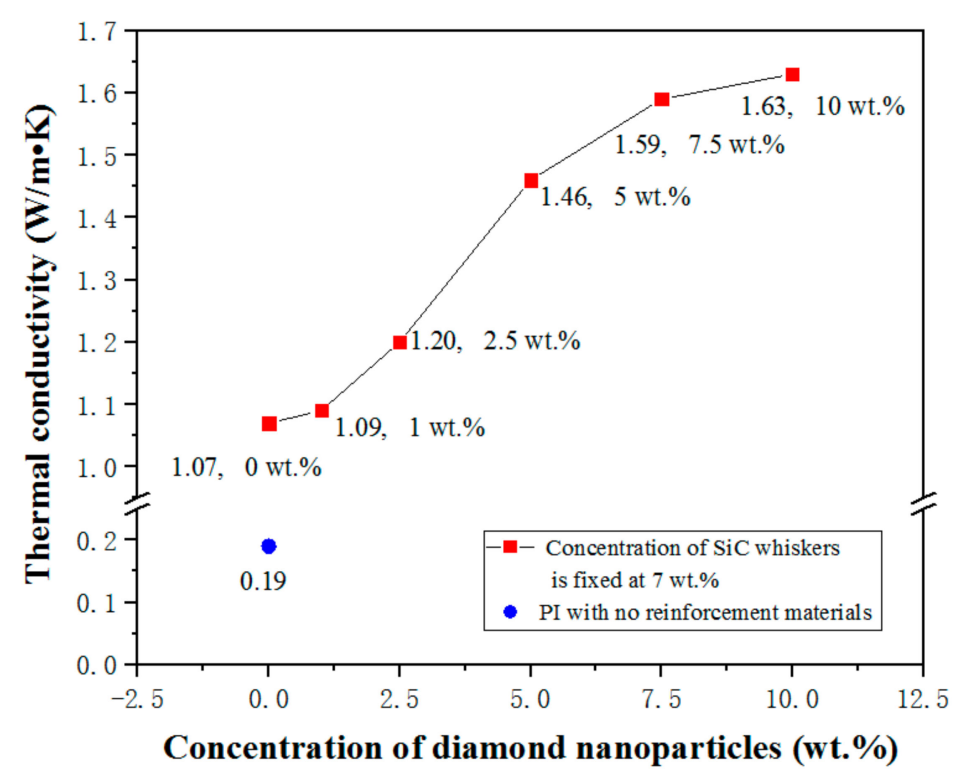

Figure 6. Thermal conductivity of the composite versus different DN concentrations.

\subsection{CTE}

The CTE of the composite was measured by the dilatometer (DIL 402, Netzsch). As shown in Figure 7, the CTE (at room temperature of $25^{\circ} \mathrm{C}$ ) of PI decreased from $55.6 \mathrm{ppm} /{ }^{\circ} \mathrm{C}$ to $25.6 \mathrm{ppm} /{ }^{\circ} \mathrm{C}$ after the addition of $7 \mathrm{wt} \% \mathrm{SCWs}$. It continued to decrease from $25.6 \mathrm{ppm} /{ }^{\circ} \mathrm{C}$ to $16.7 \mathrm{ppm} /{ }^{\circ} \mathrm{C}$ as the concentration of DNs increased from $0 \mathrm{wt} \%$ to $10 \mathrm{wt} \%$. The decrease of the CTE could be attributed to two factors. Firstly, the addition of DNs and SCWs which have low CTE reduced the total CTE of the composite. Secondly, the expansion or contraction of the matrix was restrained effectively by the particle-whisker network structures due to their strong interaction. 


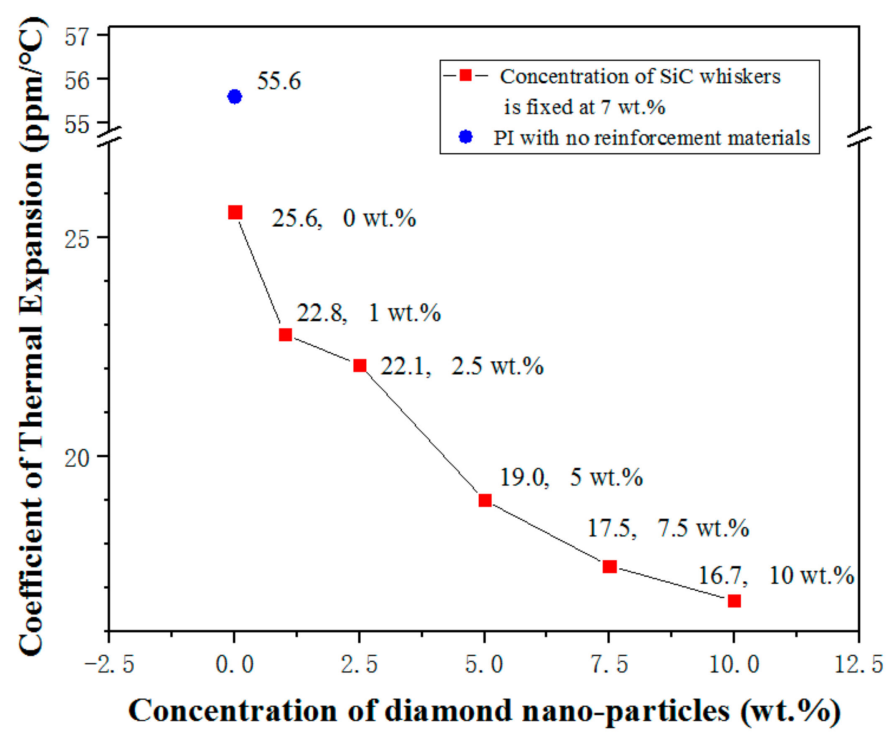

Figure 7. Coefficient of thermal expansion (CTE) of the composite versus different DN concentrations.

\subsection{Other Properties}

As discussed before, besides the enhancement of thermal conductivity and the reduction of CTE, it is essential for the composite to maintain its electrical and mechanical properties to be used as spin-coating dielectrics. The dielectric property, insulation property and mechanical strength of the composite with the optimized component ratio were tested and the results are shown in Table 1. The corresponding properties of the PI matrix are also listed for comparison. The mechanical strength of the PI matrix was enhanced by the reinforcement materials. The tensile strength increased from $81 \mathrm{MPa}$ to $145 \mathrm{MPa}$ and the Young's modulus increased from 2.5 GPa to 8.4 GPa, at the cost of the reduction of elongation at break from $7.2 \%$ to $3.3 \%$. Affected by the poor dielectric properties of the reinforcement materials, the relative permittivity of the composite increased to 4.6 compared with that of the PI matrix of 3.5 at $1 \mathrm{MHz}$. The addition of $\mathrm{SiC}$ which has a relatively low resistivity made the volume resistivity decrease from $4.3 \times 10^{7} \Omega \cdot \mathrm{cm}$ to $2.1 \times 10^{7} \Omega \cdot \mathrm{cm}$. Although the elongation at break, dielectric property and insulation property were degraded to some degree, the degradation is still acceptable.

Table 1. The properties of the composite (10 wt $\%$ DNs, $7 \mathrm{wt} \% \mathrm{SCWs})$ compared with the PI matrix.

\begin{tabular}{|c|c|c|c|c|c|c|c|}
\hline & $\begin{array}{l}\text { Thermal } \\
\text { Conductivity } \\
(\mathrm{W} / \mathrm{m} \cdot \mathrm{K})\end{array}$ & $\begin{array}{c}\text { Coefficient of } \\
\text { Thermal Expansion } \\
\left(\mathrm{ppm} /{ }^{\circ} \mathrm{C}\right)\end{array}$ & $\begin{array}{c}\text { Tensile } \\
\text { Strength } \\
(\mathrm{MPa})\end{array}$ & $\begin{array}{l}\text { Young's } \\
\text { Modulus } \\
\text { (GPa) }\end{array}$ & $\begin{array}{c}\text { Elongation } \\
\text { at Break } \\
(\%)\end{array}$ & $\begin{array}{l}\text { Relative } \\
\text { Permittivity } \\
\text { at } 1 \mathrm{MHz}\end{array}$ & $\begin{array}{c}\text { Volume Resistivity } \\
\text { at } 1 \mathrm{MHz} \\
(\Omega \cdot \mathrm{cm})\end{array}$ \\
\hline PI & 0.19 & 55.6 & 81 & 2.5 & 7.2 & 3.5 & $4.3 \times 10^{7}$ \\
\hline DN/S-CW/PI & 1.63 & 16.7 & 145 & 8.4 & 3.3 & 4.6 & $2.1 \times 10^{7}$ \\
\hline
\end{tabular}

\section{Application as Interposer RDL Dielectric}

To verify the feasibility of the composite to be used as interposer RDL dielectric, interposer test samples were fabricated. Moreover, to evaluate the effects of the composite on the improvement of interposer properties, thermal-mechanical simulations and thermal distribution tests were performed.

The fabrication process of the interposer RDL is shown in Figure 8. The routing layers were fabricated by $\mathrm{Cu}$ electroplating and the dielectrics were formed by spin-coating. It is worth noting that the PI matrix was no longer patternable due to the insoluble reinforcement materials. Thus, holes (openings in the dielectric to connect the adjacent routing layers) could not be formed by patterning. An electroplating-coating-polishing process was developed for the connection of the adjacent routing layers. First, connecting pillars were fabricated on the lower routing layer. Then the composite was 
spin-coated to cover the routing layer and the connecting pillars. At last, a polishing process was performed to reveal the connecting pillars for the connection with the upper routing layer.

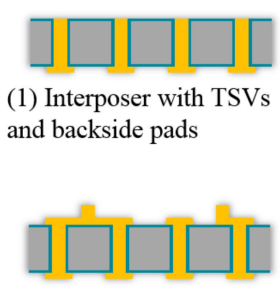

(4) Remove of the photoresist and electroplating seed layer

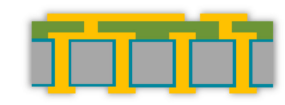

(7) Fabrication of the second layer of RDI

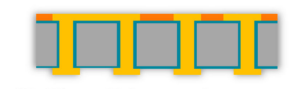

(2) Photolithography patterning and electroplating to form the first layer of RDL

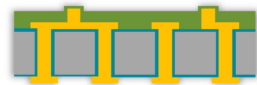

(5) Spin-coating of the dielectric material (PI or the proposed composite) and curing

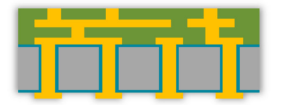

(8) Repeating of step 3-7 to form more routing layers and dielectric layers

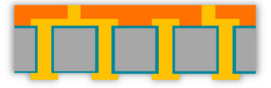

(3) Photolithography patterning and electroplating to form the connecting pillar

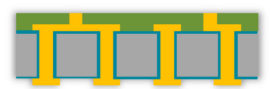

(6) Connecting pillar reveal by polishing process
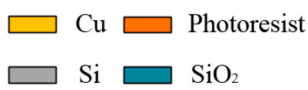

$\square$ The composite/PI dielectric

Figure 8. The fabrication process of the interposer redistribution layer (RDL).

Interposer samples with both PI dielectric and the composite dielectric (10 $\mathrm{wt} \% \mathrm{DNs}$ and $7 \mathrm{wt} \%$ SCWs) were fabricated, as shown in Figure 9. Cu routing layers, substrates and TSVs of the two samples were exactly the same. TSVs were arranged on the periphery of the interposer and two $\mathrm{Cu}$ routing layers were fabricated on the front side. It can be seen that, the DN/SCW/PI composite dielectric is opaque, unlike the transparent PI dielectric. The specifications for the components of the interposer are listed in Table 2.

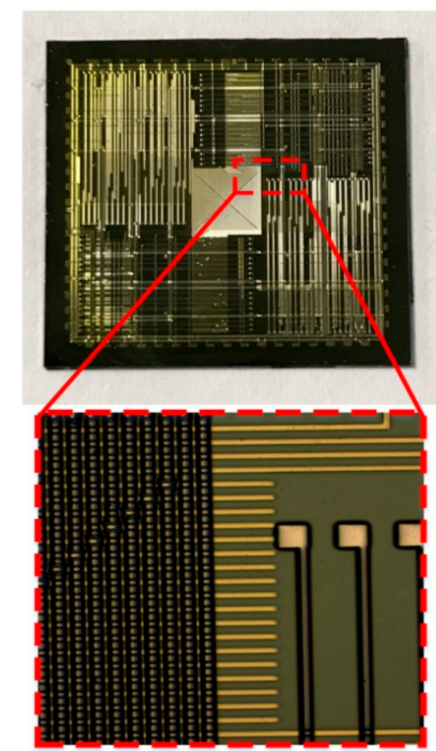

(a)

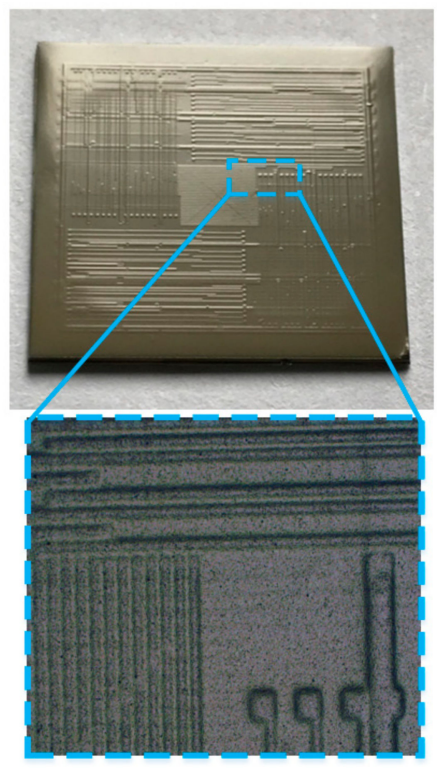

(b)

Figure 9. (a) Interposer sample with PI dielectric and (b) interposer sample with the composite dielectric.

Table 2. Specifications for all components of the interposer test sample.

\begin{tabular}{ccc}
\hline Components & Materials & Dimensions \\
\hline Interposer substrate & $\mathrm{Si}$ & Length $=10 \mathrm{~mm}$, Width $=10 \mathrm{~mm}$, Thickness $=0.2 \mathrm{~mm}$ \\
TSV & $\mathrm{Cu}$ & Radius $=40 \mu \mathrm{m}$, Height $=200 \mu \mathrm{m}$ \\
RDL routing layer & $\mathrm{Cu}$ & Thickness $=6 \mu \mathrm{m}$, Width $=60 \mu \mathrm{m}$, Line space $=60 \mu \mathrm{m}$ \\
RDL dielectric & PI/Composite & Thickness $=6 \mu \mathrm{m}$ \\
\hline
\end{tabular}


Finite element analyses (FEA) were performed to investigate the temperature distribution, von Mises stress distribution and the warpage of the two different interposers. Comparisons were made to evaluate the effects of the composite dielectric on the properties enhancement of the interposer. In the simulation model, a heating chip with a power density of $20 \mathrm{~W} / \mathrm{cm}^{2}$ was assembled on the interposer. The heat was supposed to dissipate from the backside of the interposer which was set to be at the environment temperature of $17^{\circ} \mathrm{C}$. The thermal convection and radiation were neglected in the simulation, since the die surface in a real packaged chip is always covered with a thick layer of protecting polymer which hinders the thermal convection and radiation.

As shown in Figure 10, the DN/SCW/PI composite RDL dielectric significantly enhanced the thermal-mechanical properties of the interposer compared with the PI dielectric. The maximum temperature of the interposer could be reduced from $47^{\circ} \mathrm{C}$ to $26.8^{\circ} \mathrm{C}$ and the temperature difference (Tmax - Tmin) decreased from $20^{\circ} \mathrm{C}$ to $9.8^{\circ} \mathrm{C}$, mainly due to the significant increase of the thermal conductivity of the dielectric material. The maximum von Mises stress decreased from $72.8 \mathrm{MPa}$ to 16.9 $\mathrm{MPa}$ and the warpage decreased from $1.13 \mu \mathrm{m}$ to $0.15 \mu \mathrm{m}$. These two improvements could be attributed to three factors, the reduction of the thermal gradient, the reduction of the CTE and the increase of the Young's modulus of the dielectric [15]. From the heat flow and the temperature of both sides of the interposer, the thermal resistances of the interposers can be calculated, which were $8.04^{\circ} \mathrm{C} / \mathrm{W}$ (PI dielectric) and $1.15^{\circ} \mathrm{C} / \mathrm{W}$ (the composite dielectric), respectively.
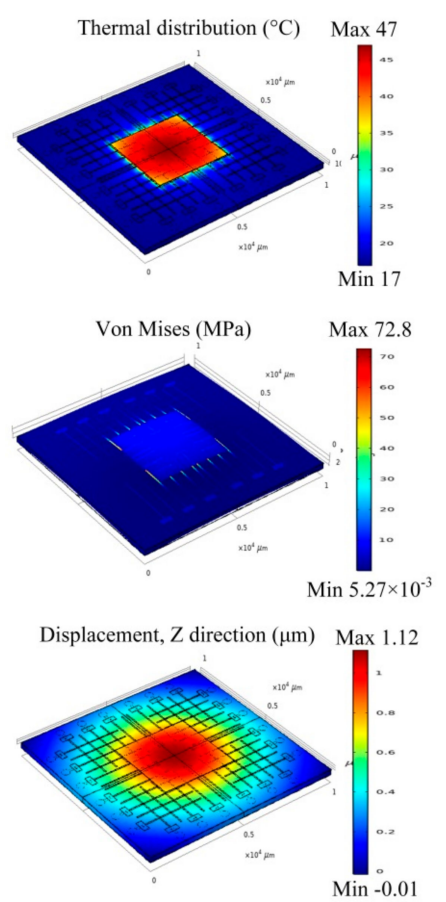

(a)
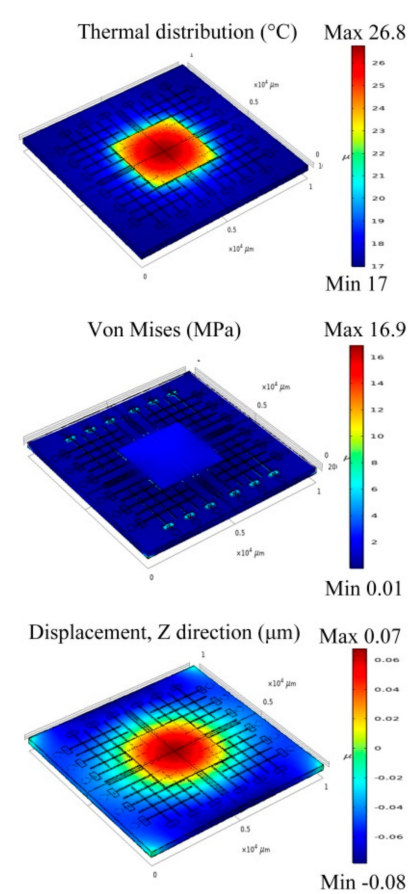

(b)

Figure 10. The thermal distribution, von Mises stress and warpage of the interposers with (a) PI dielectric and (b) the proposed composite dielectric.

The thermal distributions of the interposers with different RDL dielectrics were also investigated by experiments. A heating chip with a power density of $20 \mathrm{~W} / \mathrm{cm}^{2}$ was attached to the interposer by thermal grease and the interposer was attached to a metal heat sink. The thermal distributions were recorded by an infrared camera. As shown in Figure 11, the maximum temperature of the interposer with the composite dielectric was $45.1^{\circ} \mathrm{C}$ and that of the interposer with PI dielectric was $64{ }^{\circ} \mathrm{C}$. The temperature differences of the interposers were $46.6^{\circ} \mathrm{C}$ and $26.8^{\circ} \mathrm{C}$, respectively. The experimental values were greater than the simulated results, which could be attributed to the high thermal resistance of the thermal grease (leading to an extra interface thermal resistance). However, the experimental 
result proved that the DN/SCW/PI composite is very effective in the enhancement of the thermal property of the interposer. Figure 11 also shows that the $\mathrm{Cu}$ routing layer had an obvious temperature difference with the PI dielectric, which may cause stress concentration and lead to reliability issues. However, in the DN/SCW/PI composite dielectric, the temperature of the Cu routing layer was almost the same as that of the dielectric, benefiting from the surrounding high thermal conductivity composite.

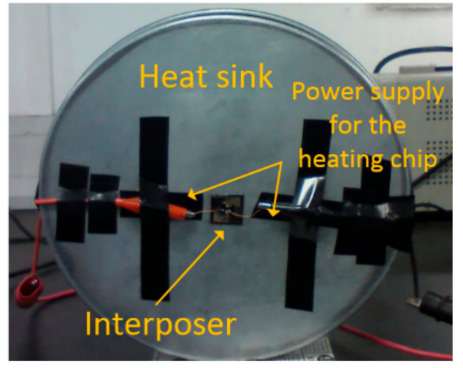

(a)

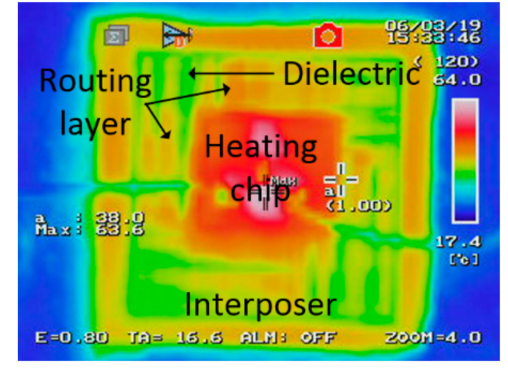

(b)

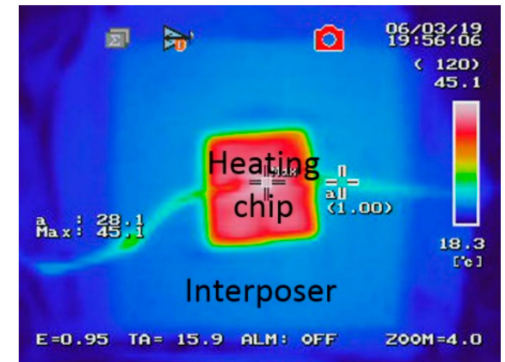

(c)

Figure 11. (a) The thermal distribution test sample. (b) Thermal distribution of the interposer with PI dielectric. (c) Thermal distribution of the interposer with the proposed composite dielectric.

\section{Conclusions}

In this paper, a high thermal conductivity and low CTE composite with PI matrix and DN/SCW reinforcement is proposed. A preparation method of the composite film is developed, in which the two reinforcement materials are pre-dispersed respectively. By this preparation method, a good dispersion result can be obtained and the whiskers and particles are randomly distributed in the matrix.

A series of tests are carried out to evaluate the performance of this composite film. The thermal conductivity and the CTE of the composite film are tested when the mass fraction of the SCWs is fixed at $7 \mathrm{wt} \%$ and the mass fraction of the DNs is $0 \mathrm{wt} \%, 1 \mathrm{wt} \%, 2.5 \mathrm{wt} \%, 5 \mathrm{wt} \%, 7.5 \mathrm{wt} \%$ and $10 \mathrm{wt} \%$, respectively. As the concentration of the DNs increases, the thermal conductivity increases and the CTE decreases. When the concentrations of the DNs and SCWs are $7 \mathrm{wt} \%$ and $10 \mathrm{wt} \%$ respectively, the composite film has the maximum thermal conductivity of $1.63 \mathrm{~W} / \mathrm{m} \cdot \mathrm{K}$ and the minimum CTE of $16.7 \mathrm{ppm} /{ }^{\circ} \mathrm{C}$ (compared with $0.19 \mathrm{~W} / \mathrm{m} \cdot \mathrm{K}$ and $55.6 \mathrm{ppm} /{ }^{\circ} \mathrm{C}$ of PI). The dielectric property, insulation property and mechanical strength of the composite film are also tested with the optimized component ratio. The results show that the electrical and mechanical properties of the composite are eligible for spin-coating dielectric, although some properties are degraded to some degree, at the cost of the improvement of thermal conductivity and CTE.

Interposer test samples are fabricated and the effects of the composite on the improvement of the interposer properties are investigated. Simulations by FEA are performed and the results indicate that the DN/SCW/PI composite used as an RDL dielectric has significantly enhanced the thermal-mechanical properties of the interposer compared with the PI dielectric. The thermal resistances of the interposer decreases from $8.04{ }^{\circ} \mathrm{C} / \mathrm{W}$ to $1.15^{\circ} \mathrm{C} / \mathrm{W}$ and the temperature difference decreases from $20^{\circ} \mathrm{C}$ to $9.8^{\circ} \mathrm{C}$. The maximum von Mises stress decreases from 72.8 MPa to $16.9 \mathrm{MPa}$ and the warpage decreases from $1.13 \mu \mathrm{m}$ to $0.15 \mu \mathrm{m}$.

The thermal distributions of the interposers with different RDL dielectrics are also investigated by experiments. The result shows that, compared with the PI dielectric, the composite dielectric can reduce the maximum temperature of the interposer from $64^{\circ} \mathrm{C}$ to $45.1^{\circ} \mathrm{C}$, the temperature difference from $46.6^{\circ} \mathrm{C}$ and $26.8^{\circ} \mathrm{C}$.

The composite can significantly reduce the temperature and enhance the reliability of the interposer chips. As a matter of experience, for every $10^{\circ} \mathrm{C}$ increase in the junction temperature, the lifetime of the chip will be reduced by about half [31]. Thus, the composite can extend the lifetime of the interposer chips as well. In conclusion, the composite developed in this study can enhance the properties of the 
interposer chips and has the potential to expand the application of the interposers, especially in high thermal density integration and high reliability devices.

Author Contributions: Conceptualization, G.D. and J.L.; methodology, J.L. and Y.S.; software, Y.W. and J.L.; validation, X.Z., G.D.; formal analysis, J.L. and Y.W.; investigation, Y.L. and G.W.; resources, G.D.; data curation, J.L.; writing-original draft preparation, J.L.; writing—review and editing, Y.S. and G.W.; visualization, Y.W.; supervision, X.Z.; project administration, G.D.; funding acquisition, G.D.

Funding: This research was funded by China Postdoctoral Science Foundation (2018M630440).

Acknowledgments: The authors would like to thank supports from the Shanghai Professional Technical Service Platform for Non-Silicon Micro-Nano Integrated Manufacturing.

Conflicts of Interest: The authors declare no conflict of interest.

\section{References}

1. Lau, J.H. Overview and outlook of three-dimensional integrated circuit packaging, three-dimensional Si integration, and three-dimensional integrated circuit integration. J. Electron. Packag. 2014, 136, 040801. [CrossRef]

2. Yazdani, F. A novel low cost, high performance and reliable silicon interposer. In Proceedings of the 2015 IEEE Custom Integrated Circuits Conference (CICC), San Jose, CA, USA, 28-30 September 2015; pp. 1-6.

3. Hong, T.Y.; Li, K.M.; Tang, C.W. Innovative through-silicon-via formation approach for wafer-level packaging applications. J. Micromech. Microeng. 2012, 22, 45019-45026.

4. Shin, S.-H.; Kim, T.-Y.; Park, J.-H.; Suh, S.-J. Optimization of Additive and Current Conditions for Void-Free Filled Through-Silicon Via. Appl. Sci. 2018, 8, 2135. [CrossRef]

5. Knickerbocker, J.; Andry, P.; Colgan, E.; Dang, B.; Dickson, T.; Gu, X.; Haymes, C.; Jahnes, C.; Liu, Y.; Maria, J. $2.5 \mathrm{D}$ and $3 \mathrm{D}$ technology challenges and test vehicle demonstrations. In Proceedings of the 2012 IEEE 62nd Electronic Components and Technology Conference (ECTC), San Diego, CA, USA, 29 May-1 June 2012; pp. 1068-1076.

6. Matsuo, M.; Hayasaka, N.; Okumura, K.; Hosomi, E.; Takubo, C. Silicon interposer technology for high-density package. In Proceedings of the 2000 50th Electronic Components and Technology Conference (Cat. No. 00CH37070), Las Vegas, NV, USA, 21-24 May 2000; pp. 1455-1459.

7. Sunohara, M.; Tokunaga, T.; Kurihara, T.; Higashi, M. Silicon interposer with TSVs (through silicon vias) and fine multilayer wiring. In Proceedings of the 2008 58th Electronic Components and Technology Conference, Lake Buena Vista, FL, USA, 27-30 May 2008; pp. 847-852.

8. So, Y.-H.; Garrou, P.; Im, J.-H.; Scheck, D.M. Benzocyclobutene-based polymers for microelectronics. Chem. Innov. 2001, 31, 40-47.

9. Harper, C. Electronic Packaging and Interconnection Handbook; McGraw-Hill, Inc.: New York, NY, USA, 2004.

10. Borst, C.L.; Gill, W.N.; Gutmann, R.J. Chemical-Mechanical Polishing of Low Dielectric Constant Polymers and Organosilicate Glasses: Fundamental Mechanisms and Application to IC interconnect Technology; Springer Science \& Business Media: New York, NY, USA, 2013.

11. Lau, J.H.; Yue, T.G. Thermal management of 3D IC integration with TSV (through silicon via). In Proceedings of the 2009 59th Electronic Components and Technology Conference, San Diego, CA, USA, 26-29 May 2009; pp. 635-640.

12. Cale, T.S.; Lu, J.-Q.; Gutmann, R.J. Three-dimensional integration in microelectronics: Motivation, processing, and thermomechanical modeling. Chem. Eng. Commun. 2008, 195, 847-888. [CrossRef]

13. Pinel, S.; Marty, A.; Tasselli, J.; Bailbe, J.-P.; Beyne, E.; Van Hoof, R.; Marco, S.; Morante, J.R.; Vendier, O.; Huan, M. Thermal modeling and management in ultrathin chip stack technology. IEEE Trans. Compon Pack Technol. 2002, 25, 244-253. [CrossRef]

14. Liu, Y.; Sun, Y.; Yan, W.; Ding, G.; Sun, B.; Zhao, X. A complex reinforced polymer interposer with ordered Ni grid and $\mathrm{SiC}$ nano-whiskers polyimide composite based on micromachining technology. Electron. Mater. Lett. 2017, 13, 29-36. [CrossRef]

15. Sun, Y.; Jin, Z.; Luo, J.; Li, J.; Sun, Y.; Wang, Y.; Ding, G. Modeling and fabrication of the redistribution layer on the 2.5 D Si interposer. In Proceedings of the 2017 18th International Conference on Electronic Packaging Technology (ICEPT), Harbin, China, 16-19 August 2017; pp. 157-161. 
16. $\mathrm{Xu}, \mathrm{X}$.; Wang, Z. Non-covalent dispersed carbon nanotube-benzocyclobutene composites as a bonding interface material for three-dimensional integration. Microelectron. Eng. 2012, 91, 33-38. [CrossRef]

17. Anri, N.; Atsushi, S.; Kei, Y.; Nobuhide, S. Novel polymer composite having diamond particles and boron nitride platelets for thermal management of electric vehicle motors. Jpn. J. Appl. Phys. 2016, 55, 027101.

18. Xie, S.-H.; Zhu, B.-K.; Li, J.-B.; Wei, X.-Z.; Xu, Z.-K. Preparation and properties of polyimide/aluminum nitride composites. Polym. Test. 2004, 23, 797-801. [CrossRef]

19. Zhang, X.; Zhang, H.; Lin, J.; Li, L.; Wu, Q. Thermal conductivity and thermal stability enhancement of ethylene propylene diene methylene with carbon nanotube. J. Reinf. Plast. Compos. 2014, 33, 767-774. [CrossRef]

20. Liu, Z.; Ding, G.; Luo, J.; Lu, W.; Zhao, X.; Cheng, P.; Wang, Y. Improved performances of AlN/polyimide hybrid film and its application in redistribution layer. Electron. Mater. Lett. 2016, 12, 679-684. [CrossRef]

21. Choi, J.-Y.; Nam, K.-N.; Jin, S.-W.; Kim, D.-M.; Song, I.-H.; Park, H.-J.; Park, S.; Chung, C.-M. Preparation and Properties of Poly(imide-siloxane) Copolymer Composite Films with Micro- $\mathrm{Al}_{2} \mathrm{O}_{3}$ Particles. Appl. Sci. 2019, 9, 548. [CrossRef]

22. Li, T.-L.; Hsu, S.L.-C. Enhanced thermal conductivity of polyimide films via a hybrid of micro-and nano-sized boron nitride. J. Phys. Chem. B 2010, 114, 6825-6829. [CrossRef] [PubMed]

23. Tanimoto, M.; Ando, S. Effects of chain rigidity/flexibility of polyimides on morphological structures and thermal diffusivity of hBN-filled composites. Compos. Sci. Technol. 2014, 99, 103-108. [CrossRef]

24. Zhou, Y.; Yao, Y.; Chen, C.-Y.; Moon, K.; Wang, H.; Wong, C.-P. The use of polyimide-modified aluminum nitride fillers in AlN@PI/Epoxy composites with enhanced thermal conductivity for electronic encapsulation. Sci. Rep. 2014, 4, 4779. [CrossRef] [PubMed]

25. Ghosh, M. Polyimides: Fundamentals and Applications; CRC Press: Boca Raton, FL, USA, 1996.

26. Gracias, A.; Tokranova, N.; Thelen, B.; Castracane, J. Influence of diamond nanoparticles on the thermal properties of benzocyclobutene (BCB). Phys. Status Solidi (a) 2011, 208, 684-690. [CrossRef]

27. Wei, G.C.; Becher, P.F. Development of SiC-whisker-reinforced ceramics. Am. Ceram. Soc. Bull. (USA) 1985, 64, 298-304.

28. Li, L.; Chung, D. Thermally conducting polymer-matrix composites containing both AIN particles and SiC whiskers. J. Electron. Mater. 1994, 23, 557-564. [CrossRef]

29. Yorifuji, D.; Ando, S. Molecular structure dependence of out-of-plane thermal diffusivities in polyimide films: A key parameter for estimating thermal conductivity of polymers. Macromolecules 2010, 43, 7583-7593. [CrossRef]

30. Kim, C.; Choi, Y.-O.; Lee, W.-J.; Yang, K.-S. Supercapacitor performances of activated carbon fiber webs prepared by electrospinning of PMDA-ODA poly (amic acid) solutions. Electrochim. Acta 2004, 50, 883-887. [CrossRef]

31. Qiu, B. Principles and Techniques of Microsystem Packaging; Pubulishing House of Electronics Industry: Beijing, China, 2006; p. 50.

(C) 2019 by the authors. Licensee MDPI, Basel, Switzerland. This article is an open access article distributed under the terms and conditions of the Creative Commons Attribution (CC BY) license (http://creativecommons.org/licenses/by/4.0/). 